\title{
Collaborative platform development in nutrition as support for cardiovascular patients'
} rehabilitation

\section{Dan-Andrei Sitar-Tăut ${ }^{1}$, Adela-Viviana Sitar-Tăut ${ }^{2 *}$, Daniel Mican ${ }^{1}$, Angela Cozma $^{2 *}$, Olga Hilda Orăşan ${ }^{2 *}$, Crina Mureşan ${ }^{3}$, Ramona Suharoschi ${ }^{3}$, Vasile Negrean' ${ }^{2}$ Dorel Sampelean ${ }^{2}$, Romana Vulturar $^{4}$, Dumitru Tudor Zdrenghea ${ }^{5}$, Dana Pop ${ }^{5 *}$, Gabriela Dogaru ${ }^{6 *}$, Alexandra Dădârlat ${ }^{7 *}$, Adriana Fodor ${ }^{8}$}

Corresponding author: Adela-Viviana Sitar-Tăut, E-mail: adelasitar@yahoo.com,

p: $139-144$

\section{* Authors with equal contributions}

\author{
1 "Babes-Bolyai" University, Cluj-Napoca, Romania \\ 2 Department of Internal Medicine, "Iuliu Haţieganu” University of Medicine and Pharmacy Cluj-Napoca, Romania \\ ${ }^{3}$ University of Agricultural Sciences and Veterinary Medicine of Cluj-Napoca, Faculty of Food Science \&Technology \\ ${ }^{4}$ Department of Cell Biology, "Iuliu Hatieganu", University of Medicine and Pharmacy Cluj-Napoca, Romania \\ ${ }^{5}$ Clinical Rehabilitation Hospital, Department of Internal Medicine, "Iuliu Haţieganu” University of Medicine and Pharmacy, \\ Cluj-Napoca, Romania \\ ${ }^{6}$ Clinical Rehabilitation Hospital, "Iuliu Haţieganu” University of Medicine and Pharmacy, Cluj-Napoca, Romania \\ 7 „Niculae Stãncioiu” Heart Institute, Department of Internal Medicine, “Iuliu Haţieganu” University of Medicine and \\ Pharmacy Cluj-Napoca, Romania \\ ${ }^{8}$ Clinical Center of Diabetes, Nutrition, Metabolic diseases, "Iuliu Haţieganu” University of Medicine and Pharmacy Cluj-
} Napoca, Romania

\section{Abstract}

Introduction. Enrollment of patients with cardiovascular disease in rehabilitation programs may contribute to implementation of a healthy lifestyle, including by promotion of a diet adequate for each patient's profile. In this context, the current study is aimed at creating a traffic light system model allowing to obtain the development, innovation and diversification of menus and to improve the nutritional programs for this category of patients. Material and method. Based on the data provided by USDA Food Composition Databases, the composition in terms of different nutritive principles was determined for each ingredient and for each final menu. Comparison of menus depending on each nutritive principle, as well as comparison between menus and nutrient requirements according to indications for patients attending cardiovascular rehabilitation programs was made. Results. The traffic light system was developed, using color codes, comparing daily nutrient requirements with preparations' content. Conclusions. The major benefit of the traffic light system would reside in the fact that starting from classic menus, an intervention on these can be achieved, and healthier, more nutritionally balanced models can be created, according to healthy nutrition principles. These new menus will be calorically and nutritionally adapted for patients attending cardiovascular rehabilitation programs.

Key words: nutrition, rehabilitation, traffic light system,

\section{Introduction}

Cardiovascular diseases (heart failure, ischemic disease, stroke) have an increasing prevalence (approximately $48 \%$ in adults aged over 20 years), in both sexes (1). They represent the first cause of death worldwide $(1,2)$, involving increasingly higher treatment and rehabilitation costs $(1,3)$. Without any doubt, an important role in the occurrence and complications of cardiovascular diseases is played by cardiovascular risk factors. Along with smoking, obesity, diabetes mellitus, dyslipidemia, hypertension, sedentary lifestyle, unhealthy diet is one of the most important modifiable risk factors. Certainly, at present, particular emphasis is also being placed on the evaluation of new cardiovascular risk factors $(4,5)$ and their implication in the progression of cardiovascular diseases (6). The European Guidelines for the Prevention of Cardiovascular

Diseases recommend a healthy diet for all individuals, regardless of the presence or not of cardiovascular diseases (7).

According to the report of the American Heart Association in 2019 (1), about $80 \%$ of all cardiovascular diseases can be prevented through a healthy lifestyle, including a healthy diet. The data reported by the European Heart Network show that in Europe nutrition plays a primordial role regarding morbidity and mortality of cardiovascular cause (7). This is why, under conditions of an established cardiac disease, the enrollment of patients in cardiovascular rehabilitation programs may contribute to implementation of a healthy lifestyle, including by promotion of a healthy diet adequate for each patient's profile. In this context, the current study is aimed at creating a traffic light system model 
allowing to obtain the development, innovation and diversification of menus and to improve the nutritional programs in patients undergoing cardiovascular rehabilitation.

\section{Methodology of the research - Practical} development of the traffic light system

The co-authors have strong expertise not only in their specific fields, but also in applying IT\&C related knowledge and skills to various medicine areas, as shown by the following works (8-13).

This time we designed a small collaborative environment to support the traffic light related research by using basic ITC tools adapted to nontechnical, but comfortable user experience and preexisting data structure and layout given by Nutritional DB.

In terms of Design Science research (14), our design problem can be formulated as follows:

- We aim to improve collaboration, data processing and analyze support effectiveness...

1. ...by developing a comfortable ITC-based platform...

2. ...that allows the medical staff to design a traffic light system...

3. ...in order to maximize utility for people to make better and informed nutritional choices.

According to the conceptual design depicted in ERD, its relational mapping was first projected in individual sheets via Google Sheets to ensure data sharing and collaborative work among team members spread in different locations.

\section{Preliminary results}

STAGE I - based on the data provided by USDA Food Composition Databases https://ndb.nal.usda.gov/ndb/search/list, the composition in terms of different nutritive principles was determined for each ingredient:

1. Saturated and polyunsaturated fatty acids 04:00, 06:00, 08:00, 10:00,12:00, 14:00, 16:00, 18:00, 20:00, 22;00, 24:00;

- Proteins - including 20 amino acids - leucine, lysine, methionine, valine, arginine, histidine;

Carbohydrates - different types, e.g. fiber, fructose, lactose, maltose, sucrose, galactose;

Vitamins - group B vitamins, folates, vitamins A, C, $\mathrm{E}, \mathrm{D}, \mathrm{K}$, riboflavin; flavonoids;

Minerals - calcium, magnesium, iron, selenium, zinc, copper;
Energy and total amount of lipids, proteins and carbohydrates.

The centralization of these data for each ingredient led to the creation of a database.

STAGE II - determination of composition in terms of different nutritive principles of the final preparations (soups/basic preparations/garnishes) based on connections established between recipes ingredients used - amounts - nutritive principles.

STAGE III - comparison of preparations depending on each nutritive principle, as well as comparison between menus and nutrient requirements according to indications for patients attending cardiovascular rehabilitation programs.

Color codes were used to develop the traffic light system: green - if all daily nutrient requirements were met, yellow - if the studied preparation met more than $60 \%$ of the daily nutrient requirements, attention being drawn to the fact that the rest of the daily requirements had to be met by the other preparations consumed, and red - if the amount provided by the studied preparation was less than $60 \%$ of the daily requirements. In the case of "unhealthy" nutritive principles (e.g. salt), the system of values was reversed - the preparation being assigned the red color if the value exceeded the limit admitted for the studied age category.

The stages of the development of the traffic light system are presented in Figure 1, and the practical exemplification of the result (for several preparations) is shown in Figure 2.

\section{Discussions}

The application of IT\&C tools in other areas than the field of computers and particularly in medicine is considered to be promising; modern methods can facilitate both the discovery of new knowledge and the increase in the practical applicability of existing knowledge. They can be included in cardiovascular rehabilitation programs, which during stages I and II are conducted in an organized setting - in hospital or on an outpatient basis (15). The team involved in this program is complex, including, in addition to a cardiologist, nurses, a psychologist/psychiatrist and a kinesiotherapist, a nutritionist. 
Fig. 1.- Traffic light system development process flow

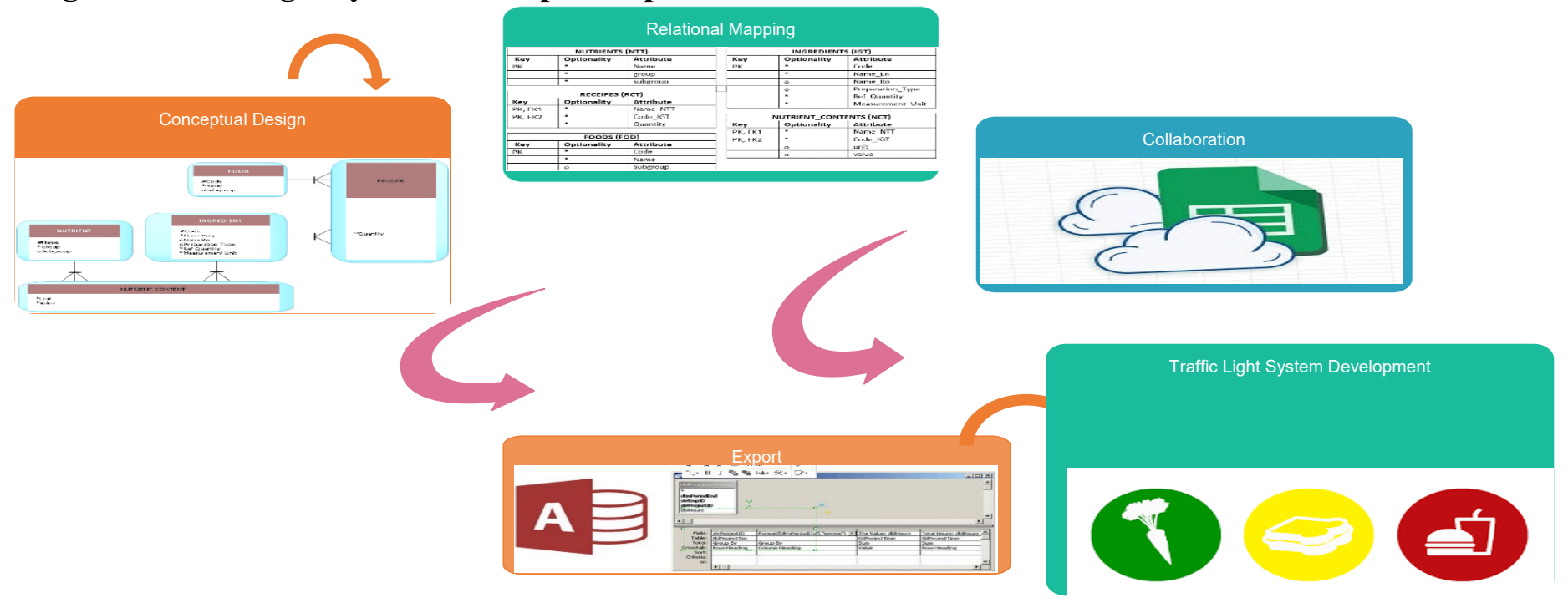

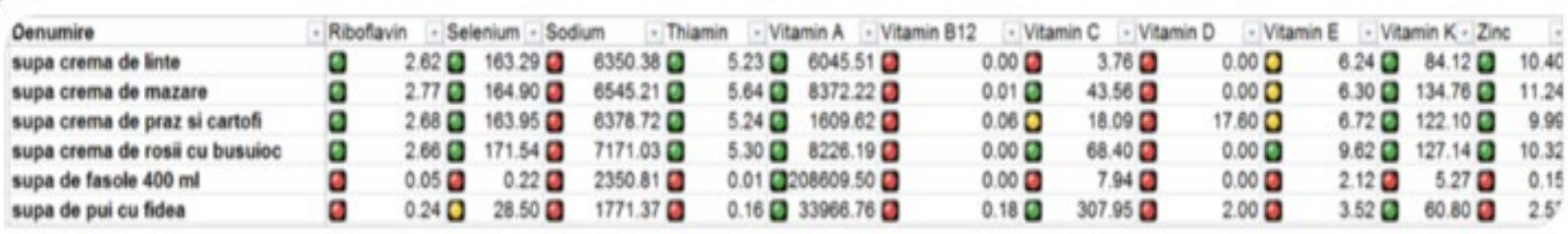

Fig. 2. - Traffic light system results - exemplification

Exemplification for: lentil cream soup, green peas cream soup, leek and potato cream soup, tomato and basil cream soup, bean soup, and chicken and noodle soup

After the data population process, the cloud stored file was exported locally, cleaned up, mapped to a database structure, and then analyzed with MS Access tools such as cross-tabs and other various query types. The short time period during which the patient with myocardial infarction treated interventional is hospitalized is extremely important for understanding the cardiovascular risk factors that have led to the development of the disease and for implementing lifestyle changing measures, including those concerning a healthy diet. Next, although rehabilitation is carried out in an outpatient setting (and currently, more and more often at home), the patient should be monitored and evaluated periodically from this point of view as well (16-18). In this regard, creating a "nutritional model" that can be applied to these categories of patients can be of real help.

There are few published studies on the possible uses of various informatics methods in nutrition and particularly among patients enrolled in cardiovascular rehabilitation programs. The great majority of current applications refer to the calculation of the content of lipids + proteins + carbohydrates, provide simple nutritional evaluation methods, without refined analyses and without taking into consideration the particularities and nutritional requirements of the person concerned.

Different types of diets have been studied and assessed regarding their role in the secondary prevention process (19) - Mediterranean diet - in the PREDIMED study - Prevencion con Dieta MEDiterranea $(20,21,22)$, Hellenic Heart failure study (23), DASH diet, vegetarian or vegan diets. Controversies related to vegetarian/vegan diets are multiple. The risks of these diets would be nutrient deficiencies (24), lower levels of eicosapentaenoic and docosahexaenoic acids (25-27) - acids involved in cardiovascular disease prevention $(24,28)$, lower iron stores (24), lower daily intake and serum concentrations of zinc, iodine and vitamin B12 deficiency, decreased vitamin D levels $(24,25)$ with a reduction in bone density, development of osteoporosis, spinal fractures and compression (25). However, a vegetarian diet induces an improvement in the lipid profile, blood pressure values, glycemic 
control, a decrease in abdominal obesity $(25,28-33)$, reduces salt consumption, is rich in potassium, is associated with an increase in the level of physical activity performed (34) and with fewer fatal/non-fatal events in patients with ischemic heart disease $(24,25$, $35,36)$.

The adaptation of diet to the existing cardiovascular pathology, to the desiderata imposed by the performing of the cardiovascular rehabilitation program (type of physical exercise) and to the subjects' personal characteristics (sex, current weight status, and food preferences) is an extremely sensitive and difficult to achieve process. Current prevention guidelines recommendations are a percentage of trans-unsaturated fatty acids $<1 \%$ of energy intake, consumption of $<5 \mathrm{~g}$ salt/day, limitation of alcoholic drinks and discouragement of sweetened/carbonated drinks (7).

Even if there are studies (pro and con) on the impact that certain nutrients and vitamins may have on cardiovascular pathology (selenium - (37-40), thiamine - $(41,42)$, vitamin $\mathrm{C}-(43,44)$, magnesium - (4-47), zinc (48), monitoring of intake within rehabilitation programs is rarely performed.

The study of food menus and their adaptation to patients' particularities would involve nutritional analysis from the perspective of the recipe and preparation technology, providing information related to the nutritional and energy value of the menus, salt content, fat, saturated fat, sugar and particularly nutrients, vitamins (much more rarely evaluated, as mentioned before). The analysis of menus would identify deficiencies, as well as the possibilities of improvement. At the same time, with the help of specialists in nutrition, menus might be created in accordance with the dietary beliefs of different categories of patients, to reduce nutritional deficiencies and allow effective cardiovascular rehabilitation. Despite seeming an easy process, refined analysis, with the evaluation of micronutrient and vitamin content, is very time-consuming and difficult to perform.

Implementing the traffic light system would allow the development, innovation and diversification of food menus, which would lead to reformulated, personalized menus with practical applicability (by applying knowledge of molecular gastronomy, molecular, nutrigenomic, nutriepigenetic nutrition) for patients attending cardiovascular rehabilitation programs (49-51).

\section{Conclusions}

The major benefit of the traffic light system would reside in the fact that starting from classic menus, an intervention on these can be achieved, and healthier, more nutritionally balanced models can be created, according to healthy nutrition principles. These new menus will be calorically and nutritionally adapted for patients attending cardiovascular rehabilitation programs.

Through the collaboration of the cardiologist and the nutritionist, using modern informatics methods, patients will be able to diversify their diet, while respecting the principles of healthy nutrition.

\section{Acknowledgement PN-III-P2-2.1-CI-2017-0783 grant and PN-III-P2-2.1-CI-2018- 1134 grant}

\section{REFERENCES}

1. Benjamin EJ, Muntner P, Alonso A, Bittencourt MS, Callaway CW, Carson AP et al. American Heart Association Council on Epidemiology and Prevention Statistics Committee and Stroke Statistics Subcommittee. Heart Disease and Stroke Statistics2019 Update: A Report from the American Heart Association. Circulation. 2019 Jan 3.

2. https://www.who.int/gho/ncd/en

3. Pagidipati NJ, Gaziano TA. Estimating deaths from cardiovascular disease: a review of global methodologies of mortality measurement. Circulation. 2013; 127(6):749-756.

4. Pop D, Peter P, Dădârlat A, Sitar-Tăut A, Zdrenghea D. Serum ghrelin level is associated with cardiovascular risk score. Rom. J. Internal Med. 2015; 140.

5. Pop D, Sitar-Tăut A, Bodisz G, Zdrenghea D, Cebanu M, Stanca L. Role of secretory phospholipase A2 in women with metabolic syndrome. Indian J Med Res. 2013; 138: 866-872.

6. Fodor A, Cozma A, Karnieli E. Personalized epigenetic management of diabetes. Personalized medicine. 2015 ; 12(5): 497-514.

7. Piepoli MF, Hoes AW, Agewall S, Albus C, Brotons C, Catapano AL et al. ESC Scientific Document Group. 2016 European Guidelines on cardiovascular disease prevention in clinical practice: The Sixth Joint Task Force of the European Society of Cardiology and Other Societies on Cardiovascular Disease Prevention in Clinical Practice (constituted by representatives of 10 societies and by invited experts) Developed with the special contribution of the European Association for Cardiovascular Prevention 
\& Rehabilitation (EACPR). Eur Heart J. 2016; 37(29):2315-2381.

8. Sitar-Tăut DA, Săcărea C, Sitar-Tăut AV. Knowledge Visualization for Supporting Communication in Cardiovascular Risk Assessment Hypotheses, The 23rd International Conference on Software, Telecommunications and Computer Networks (SoftCOM 2015), 16-18 September, Bol, Island of Brač, Croatia, IEEE. 2015:249 - 253 .

9. Sitar-Taut AV, Zdrenghea D, Pop D, Sitar-Taut DA. Using machine learning algorithms in cardiovascular disease risk evaluation. Journal of Applied Computer Science \& Mathematics 2009; 5(3): 29-32

10. Sitar-Taut DA, Sitar-Taut AV. Overview on How Data Mining Tools May Support Cardiovascular Disease Prediction. Journal of Applied Computer Science \& Mathematics. 2010; 8(4): 57-62.

11. Sitar-Taut DA, Sitar-Taut AV, Penciu OM, Mican D. Initiatives in the Romanian eHealth Landscape. Informatica Economica Journal. 2011; 15 (2): 38-45.

12. Sitar-Taut DA, Sitar-Taut AV, Mocean L. Research about Implementing E-Procord - New Medical and Modeling Approaches in IT\&C Age Applied on Cardiovascular Profile Evaluation at Molecular Level. Journal of Applied Quantitative Methods .2009; 4(2): 175-189.

13. Sitar-Taut DA, Sitar-Taut AV, Podean M. Electronic Records Management Proposal For Cardiovascular Risk Assessment. 1st International Scientific Conference „Educational performance and sustainable development in private higher education", Calitatea - Acces la succes 2012; 13(S2): 295-303.

14. Brandtner $P$ et al. Multi-criteria Selection in Design Science Projects - A Procedure for Selecting Foresight Methods at the Front End of Innovation, in New Horizons in Design Science: Broadening the Research Agenda, B. Donnellan, et al., Editors. 2015: 295-310.

15. Pop D, Zdrenghea D, Rosu R et al. Recuperarea cardiovasculară: manual pentru studentii de la programul de studiu Balneofiziokinetoterapie și recuperare medicală. Cluj-Napoca: Editura Medicală Universitară’Iuliu Haţieganu”, 2016.

16. Zdrenghea D. (sub red.). Recuperare şi prevenţie cardiovasculară. Ed Clusium. 2008. ISBN 978-973555-576-4

17. McMahon SR, Ades PA, Thompson PD. The role of cardiac rehabilitation in patients with heart disease. Trends Cardiovasc Med. 2017; 27(6):420-425.

18. Schröder H, Cárdenas-Fuentes G, Martínez-González MA, Corella D, Vioque J, Romaguera D et al. PREDIMED-Plus investigators. Effectiveness of the physical activity intervention program in the PREDIMED-Plus study: a randomized controlled trial. Int J Behav Nutr Phys Act. 2018; 15(1):110.
19. Panagiotakos DB, Notara V, Kouvari M, Pitsavos C. The Mediterranean and other Dietary Patterns in Secondary Cardiovascular Disease Prevention: A Review. Curr Vasc Pharmacol. 2016; 14(5):442-451.

20. Martínez-González MA, Salas-Salvadó J, Estruch R, Corella D, Fitó M, Ros E; PREDIMED INVESTIGATORS Benefits of the Mediterranean Diet: Insights From the PREDIMED Study. Prog Cardiovasc Dis. 2015; 58(1):50-60 .

21. Salas-Salvadó J, Díaz-López A, Ruiz-Canela M, Basora J, Fitó M, Corella D et al.; PREDIMED-Plus investigators. Effect of a Lifestyle Intervention Program With Energy-Restricted Mediterranean Diet and Exercise on Weight Loss and Cardiovascular Risk Factors: One-Year Results of the PREDIMEDPlus Trial. Diabetes Care 2018 Epub ahead of print.

22. Agarwal A, Ioannidis JPA. PREDIMED trial of Mediterranean diet: retracted, republished, still trusted? BMJ. 2019; 364:1341.

23. Kouvari M, Chrysohoou C, Aggelopoulos P, Tsiamis E, Tsioufis K, Pitsavos C, Tousoulis D. Mediterranean diet and prognosis of first-diagnosed Acute Coronary Syndrome patients according to heart failure phenotype: Hellenic Heart Failure Study. Eur J Clin Nutr. 2017 Epub ahead of print.

24. Melina V, Craig W, Levin S. Position of the Academy of Nutrition and Dietetics: Vegetarian Diets. J Acad Nutr Diet. 2016; 116:1970-1980.

25. Appleby PN, Key TJ. The long-term health of vegetarians and vegans. Proc Nutr Soc. 2016; 75(3):287-293.

26. Saunders AV, Davis BC, Garg ML. Omega-3 polyunsaturated fatty acids and vegetarian diets. Med J Aust. 2013; 199 (4):S22-S26.

27. Sanders TA. DHA status of vegetarians. Prostaglandins Leukot Essent Fatty Acids. 2009; 81(2-3):137-141.

28. Rosell MS, Lloyd-Wright Z, Appleby PN, et al. Long-chain n-3 polyunsaturated fatty acids in plasma in British meateating, vegetarian, and vegan men. Am J Clin Nutr. 2005;82(2):327-334.

29. Rizzo NS, Sabaté J, Jaceldo-Siegl K, Fraser GE. Vegetarian dietary patterns are associated with a lower risk of metabolic syndrome: The Adventist Health Study 2. Diabetes Care. 2011; 34(5):12251227 .

30. Pettersen BJ, Anousheh R, Fan J, Jaceldo- Siegl K, Fraser GE. Vegetarian diets and blood pressure among white subjects: Results from the Adventist Health Study-2 (AHS-2). Public Health Nutr. 2012; 15(10):1909-1916.

31. Wang F, Zheng J, Yang B, Jiang J, Fu Y, Li D. Effects of vegetarian diets on blood lipids: A systematic review and metaanalysis of randomized controlled trials. J Am Heart Assoc. 2015; 4(10): e002408 
32. Barnard ND, Katcher HI, Jenkins DJ, Cohen J, Turner-McGrievy G. Vegetarian and vegan diets in type 2 diabetes management. Nutr Rev. 2009;67(5):255-263.

33. Tonstad S, Butler T, Yan R, Fraser GE. Type of vegetarian diet, body weight and prevalence of type 2 diabetes. Diabetes Care. 2009;32(5):791-796.

34. Garbett T, Garbett DL, Wendorf A. Vegetarian Diet: A Prescription for High Blood Pressure? A Systematic Review of the Literature. The Journal for Nurse Practitioners. 2016; 12:452-458.

35. Orlich MJ, Singh PN, Sabaté J, et al. Vegetarian dietary patterns and mortality in Adventist Health Study 2. JAMA Intern Med. 2013;173(13):12301238.

36. Crowe FL, Appleby PN, Travis RC, Key TJ. Risk of hospitalization or death from ischemic heart disease among British vegetarians and nonvegetarians: Results from the EPIC-Oxford cohort study. Am J Clin Nutr. 2013;97 (3):597-603.

37. Mirmohammadsadeghi A, Gharipour M, Roohafza H, Dianatkhah M, Sadeghi M. Effects of selenium supplementation on paraoxonase-1 and myeloperoxidase activity in subjects with cardiovascular disease: the Selenegene study, a double-blind randomized controlled trial. Arch Med Sci Atheroscler Dis. 2018;3: e112-e118.

38. Zhu ML, Wang G, Wang H, Guo YM, Song P, Xu J, Li P, Wang S, Yang L. Amorphous nano-selenium quantum dots improve endothelial dysfunction in rats and prevent atherosclerosis in mice through $\mathrm{Na}+/ \mathrm{H}+$ exchanger 1 inhibition.Vascul Pharmacol. 2019 Jan 26. Epub ahead of print .

39. Rees K, Hartley L, Day C, Flowers N, Clarke A, Stranges S. Selenium supplementation for the primary prevention of cardiovascular disease. Cochrane Database Syst Rev. $2013 ;(1)$.

40. Gharipour M, Sadeghi M, Behmanesh M, Salehi M, Nezafati P, Gharpour A. Selenium Homeostasis and Clustering of Cardiovascular Risk Factors: A Systematic Review. Acta Biomed. 2017;88(3):263270 .

41. Wong EKC, Lee JY, Leong DP, Mbuagbaw L, Yousuf H, Keen S, Straus SE, Patterson CJ, Demers C. Thiamine versus placebo in older heart failure patients: study protocol for a randomized controlled crossover feasibility trial (THIAMINE-HF). Pilot Feasibility Stud. 2018; 4:149 .

42. DiNicolantonio JJ, Liu J, O'Keefe JH. Thiamine and Cardiovascular Disease: A Literature Review. Prog Cardiovasc Dis. 2018; 61(1):27-32.

43. Ashor AW, Brown R, Keenan PD, Willis ND, Siervo M, Mathers JC. Limited evidence for a beneficial effect of vitamin $\mathrm{C}$ supplementation on biomarkers of cardiovascular diseases: an umbrella review of systematic reviews and meta-analyses. Nutr Res. $2019 ; 61: 1-12$.

44. Lee CH, Chan RSM, Wan HYL, Woo YC, Cheung CYY, Fong CHY, Cheung BMY, Lam TH, Janus E, Woo J, Lam KSL. Dietary Intake of Anti-Oxidant Vitamins A, C, and E Is Inversely Associated with Adverse Cardiovascular Outcomes in Chinese-A 22Years Population-Based Prospective Study. Nutrients. 2018;10(11).

45. Sobczak AIS, Stefanowicz F, Pitt SJ, Ajjan RA, Stewart AJ.Total plasma magnesium, zinc, copper and selenium concentrations in type-I and type-II diabetes. Biometals. 2019;32(1):123-138 .

46. Larsson SC, Drca N, Michaëlsson K. Serum Magnesium and Calcium Levels and Risk of Atrial Fibrillation. Circ Genom Precis Med. 2019;12(1):e002349.

47. Liu M, Jeong EM, Liu H, Xie A, So EY, Shi G, Jeong GE, Zhou A, Dudley SC Jr. Magnesium supplementation improves diabetic mitochondrial and cardiac diastolic function. JCI Insight. 2019;4(1).

48. Choi S, Liu X, Pan Z. Zinc deficiency and cellular oxidative stress: prognostic implications in cardiovascular diseases. Acta Pharmacol Sin. 2018;39(7):1120-1132.

49. Fabbri ADT, Crosby GA, 2016. A review of the impact of preparation and cooking on the nutritional quality of vegetables and legumes. Int. J. Gastron. Food Sci. 3:2-11.

50. Garcia V, Laca A, Martinez LA, Paredes B, Rendueles M, Diaz M, 2015. Development and characterization of a new sweet egg-based dessert formulation. Int. J. Gastron. Food Sci. 2(2):72-82.

51. Government Office for Science (2007) Tackling Obesities: Future Choices. http://www.bis.gov.uk/assets/foresight/docs/obesity/ 17.pdf. 